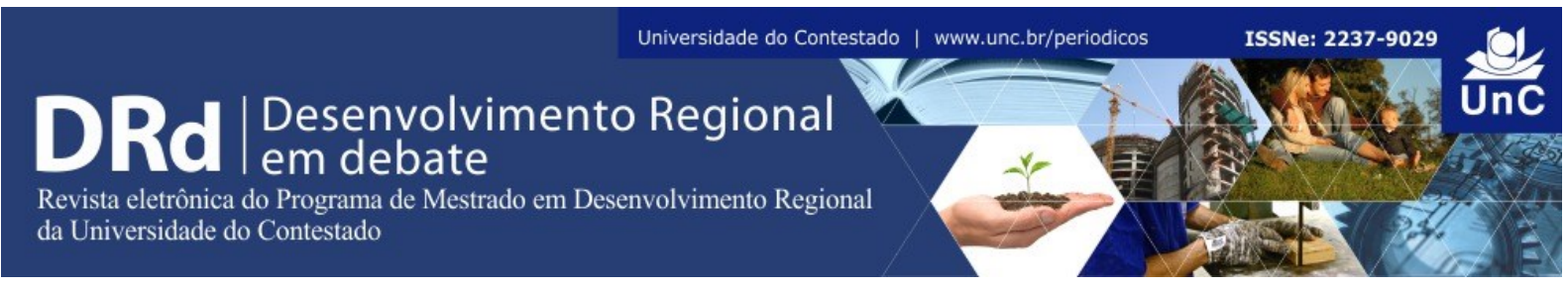

\title{
PROGRAMA PLANORTE LEITE NO CONTEXTO DO DESENVOLVIMENTO REGIONAL: A BUSCA DE UM DIFERENCIAL
}

Waldemiro Sudoski ${ }^{1}$

\section{RESUMO}

Dezoito entidades participaram da construção do Programa PLANORTE LEITE. Após seu lançamento até os dias atuais às entidades signatárias, em especial a Epagri, as Secretarias Municipais de Agricultura, IFSC/Canoinhas vem realizando as atividades de acordo com o cronograma proposto. Muitas ações já estão sendo executadas como: a organização coletiva das famílias através da formação de grupos formais e informais; encontros sistemáticos nas propriedades para um crescimento coletivo da consciência associativista e melhorias nas técnicas de produção; constituição e dinamização dos fundos municipais de desenvolvimento agrícola; projeto de avaliação da qualidade do leite e da água utilizada nas propriedades; busca e aplicação de recursos financeiros nas esferas federal e estadual para o Programa, como o apoio do SC Rural para dez grupos de famílias organizados; desenvolvimento de máquinas e equipamentos para a atividade leiteira, como plantadeira para mudas de pastagens, aquecedores para água com energia solar, biogás e lenha; contratação de consultoria para realização de estudos de viabilidade técnica e econômica de industrialização diferenciada; comprometimento das lideranças politicas com o Programa. Por ser um programa construído coletivamente por diversas entidades regionais, visualiza-se que o PLANORTE LEITE pode se tornar um marco importante para a dinamização da economia regional. Quando a meta de produção de quinhentos mil litros dia for atingida, quinze milhões de reais a cada mês estará circulando na economia local, ou seja, mais de cento e oitenta milhões por ano. Isto corresponde por ano a uma área de aproximadamente trinta e sete mil hectares de soja.

Palavras-Chaves: Desenvolvimento Territorial. Política Pública. Arranjo Produtivo Local.

\section{PROGRAM PLANOTE LEITE IN THE REGIONAL DEVELOPMENT FRAMEWORK}

\begin{abstract}
Eighteen entities participated in the construction of the program Planorte Leite. After its launch to the present day the signatory entities, especially Epagri, the Municipal Departments of Agriculture, IFSC / Canoinhas have been carrying out activities in accordance with the proposed schedule. Many actions are already being implemented such as the collective organization of families through the formation of formal and informal groups; systematic meetings in the farms for a collective growth of associative awareness and improvements in production techniques; establishment and promotion of municipal funds of agricultural development; evaluation project of milk quality and the water used in the farms; search and
\end{abstract}

\footnotetext{
${ }^{1}$ Engenheiro Agrônomo. Funcionário da Epagri, Regional de Canoinhas (SC). Santa Catarina. Brasil. E-mail: sudoski@epagri.sc.gov.br.
} 
application of financial resources at the federal and state levels to the Program, with the support of SC Rural for ten groups of organized families; development of machinery and equipment for the dairy industry, such as planter for pasture seedlings, water heaters with solar energy, biogas and firewood; consultancy contract to carry out technical and economic feasibility studies of differentiated industrialization; commitment of political leaders with the Program.Being a collectively built program by several regional entities, the PLANALTO NORTE LEITE can become an important milestone for the promotion of the regional economy. When the five hundred thousand liters a day production target is reached, fifteen million reais each month will be circulating in the local economy, or over one hundred and eighty million per year. This corresponds per year to an area of approximately thirty-seven thousand hectares of soybeans.

Keywords: Regional Development. Public Policy. Local Productive Arrangement.

\section{INTRODUÇÃO}

A pecuária de leite, já existente na região, tendo seu início na forma de produção comercial nos primeiros anos da década de 1980, atingindo e seu auge em volume de produção no início dos anos de 2000. A partir daí ocorreu uma decadência, tendo como principal motivo, questões de mercado e a possibilidade de diversificação de atividades que as propriedades agrícolas do Planalto Norte podem realizar resultando numa diminuição da produção regional equivalente a um terço atualmente. Partindo-se da premissa que a Região já produziu três vezes mais leite do que se produz hoje, a atividade foi identificada como uma das mais promissoras para o Planalto Norte Catarinense, pois as características regionais e a atual situação macroeconômica do país são favoráveis à atividade. Some-se a isso o fato de que esta atividade pode ser plenamente desenvolvida respeitando os bons preceitos da preservação e conservação ambientais, pois, o sistema de produção com base em pastagens perenes de verão e anuais de inverno, manejadas pelo método Voisin, foi definido pelo Programa.

Busca-se com o programa, propor a produção de leite com alguns diferenciais. Por exemplo, o uso de fontes alternativas de energia, para diminuir custos e a dependência da eletricidade, tão imprescindíveis neste século XXI, que além de ser uma atividade que gera uma renda mensal aos produtores, contribui para a autonomia financeira das mulheres (já que a atividade demanda mão-de-obra familiar), favorece a sucessão familiar (estimulando os jovens a permanecerem no campo), incrementa o comercio local pois as famílias suprem suas necessidades de insumos e bens de consumo em seus próprios municípios ou na Região. Também se constitui numa alternativa para a diversificação na propriedade rural, dentre outros aspectos favoráveis à disseminação da atividade na região.

Por ser uma atividade que possibilita um encadeamento muito grande entre as diversas etapas que integram a cadeia produtiva do leite, o PLANORTE LEITE pode estimular a instalação de novos empreendimentos, tais como a construção civil, a fabricação e o comércio de máquinas e equipamentos, rações, medicamentos, sementes, mudas e indústrias processadoras, beneficiando assim não somente a produção leiteira, como as demais atividades ligadas direta e indiretamente, promovendo assim o desenvolvimento regional 
O Programa Planorte Leite surgiu de uma necessidade sentida pelos Prefeitos através da Associação dos Municípios do Planalto Norte Catarinense (Amplanorte), para que este programa passe a ser um dinamizador na busca de uma organização das cadeias produtivas voltadas para a vocação da região, qual seja o setor agrícola. Embasado neste propósito se constituiu um grupo de pessoas oriundas de entidades ligadas direta ou indiretamente com a atividade e sem interesses comerciais, sob a coordenação da Amplanorte, para estruturar uma proposta que culminou em um programa, que foi lançado no dia 23 de maio de 2014, no parque de exposição Ouro Verde de Canoinhas, com expressiva participação de lideranças, técnicos e famílias de produtores e das entidades que pariciparam da construção do programa. São elas: Amplanorte; Empresa de Pesquisa Agropecuária Assistência Técnica e Extensão Rural de Santa Catarina (Epagri); Companhia Integrada de Desenvolvimento Agrìcola de Santa Catarina (Cidasc); Instituto Federal de Santa Catarina (IFSC), Campus Canoinhas; Universidade do Contestado (UnC); Forum de Secretários Municipais de Agricultura do Planato Norte de SC (Seplan); Empresa Brasileira de Pesquisa Agropecuária (Embrapa); Programa SC Rural; Serviço Nacional de Apredizagem Rural (Senar); Federação da Agricultura de Santa Catarina (Faesc); Associação dos Sindicatos de Trabalhadores Rurais da Região da Erva-mate (Astramate); Sindicato dos Trabalhadores na Agricultura Familiar (Sintraf); Serviço Brasileiro de Apoio às Micros e Pequena Empresa (Sebrae); Secretarias de Desenvolvimento Regional de Canoinhas e Mafra, atualmente Agências de Desenvolvimento Regional; Cooperativa Regional de Industrialização e Comercialização Dolcimar Luis Brunetto (Cooperdochi); Território da Cidadania do Planalto Norte catarinense; Sistema de Cooperativas de Produtores de Leite da Agricultura Familiar do Planalto Norte Catarinense (SISCLAF).

O presente texto está assim estruturado: a partir desta introdução, são apresentadas informações com o caráter metodológico e de caracterização do objeto de estudo; na sequência, apresenta-se uma contextualização e análise dos fatores que justificam um programa como o que está sendo apresentado, como alternativa de desenvolvimento da região em referência; em quarto lugar, à titulo de resultados iniciais do processo de estruturação do Planorte Leite, apresenta-se o protocolo, que demonstra o comprometimento das entidades parceiras na efetivação do programa; finaliza-se o texto, com rápidas considerações.

\section{CARACTEIZAÇÃO DO OBJETO EM ANÁLISE}

Dividimos este item em duas partes: primeiro, questões de caráter metodoógico, explicitando do que resulta o presente texto; na sequência, como caracterização do objeto em análise, apresentando a estrutura do programa PLANORTE LEITE.

Metodologicamente, o texto que apresentamos trata-se de um relato, na forma de documento informativo, transcrevendo dados e informações necessárias à divulgação do plano de incentivo à produção leiteira na região do Planalto Norte Catarinense, chamado PLANORTE LEITE. Portanto, o texto foi estruturado, resgatando atas de reuniões e documentos produzidos no processo de estruturação do programa.

Sobre o programa PLANORTE LEITE, temos a destacar os elementos abaixo mencionados.

DRd - Desenvolvimento Regional em debate (ISSNe 2237-9029) 


\section{OBJETIVOS DO PROGRAMA PLANORTE LEITE}

Iniciamos pela explicitação dos objetivos do PLANORTE LEITE.

\section{Geral:}

- Propiciar o desenvolvimento regional integrado e sustentável do Planalto Norte de $\mathrm{SC}$, por meio do fomento da cadeia produtiva do leite (PLANORTE LEITE).

\section{Específicos:}

-Integrar as entidades regionais na construção e execução do PLANORTE LEITE;

-Executar o planejamento estratégico definido de acordo com os eixos estabelecidos para o programa: a) gerenciamento; b) produção ; c) logística.

- Organizar as famílias beneficiárias para uma participação mais efetiva no programa dentro dos princípios associativos.

-Captar recursos financeiros das esferas Federal, Estadual e Municipal para apoiar as diversas etapas da execução do programa.

- Capacitar os técnicos e extensionistas (apoio técnico) em técnicas sustentáveis de produção.

- Promover a capacitação continuada dos produtores visando a excelência na produção.

-Propiciar o emprego de técnicas sustentáveis de produção do leite e seus derivados visando à segurança alimentar e a conservação e preservação ambiental.

- Promover a utilização de energias alternativas nos processos de produção para reduzir custos e a dependência da energia elétrica.

-Incrementar o comércio da microrregião com geração substancial de emprego e aumento da arrecadação tributária dos municípios.

-Incentivar a instalação ou desenvolvimento de agroindústrias processadores do leite produzido na região.

\section{ELEMENTOS SOBRE A FORMATAÇÃO DO PROGRAMA PLANORTE LEITE}

O Programa PLANORTE LEITE é composto por três grandes eixos: (i) Gerenciamento Geral; (ii) Produção; (iii)Logística. 
Gerenciamento Geral

Destacamos aqui a justificativa, os objetivos e o plano de ação.

\section{Justificativa}

O programa PLANORTE LEITE, pela sua complexidade, exigirá um processo de gestão eficiente e alocação de recursos de diversas fontes para a sua execução além do comprometimento das entidades, órgãos municipais e estaduais para que consigamos focar a valorização da produção local.

\section{Objetivos Específicos do Eixo}

a) Gestão do Programa;

b) Alocação e recursos financeiros;

c) Divulgação do Programa;

d) Integração das diversas entidades participantes para o gerenciamento financeiro do programa.

\section{Plano de Ação}

-Criação do Comitê Gestor/Executivo para cobrar/fiscalizar as ações do programa;

-Sensibilização e comprometimento da classe política compreendendo os Prefeitos, Bancada Catarinense de Deputados (Estadual e Federal);

- Verificação dos programas atuais da Secretaria de Estado da Agricultura e Pesca para o setor agrícola que venham de encontro com o Programa PLANORTE LEITE e propor a criação de novos programas específicos;

-Elaboração dos Projetos para captação de recursos;

-Criação ou revitalização dos Fundos Municipais para o Desenvolvimento do Programa;

-Divulgação do Programa nas esferas afins dos governos Municipais/Estadual/Federal capitaneada pela Associação dos Municípios - AMPLANORTE;

-Divulgação do Programa de forma integrada ao produtor rural por todas as partes envolvidas no programa. 
Produção

\section{Justificativa}

Aumentar em qualidade e quantidade da produção leiteira nas propriedades do Planalto Norte, em especial nas da agricultura familiar.

\section{Objetivo}

Promover o desenvolvimento da produção diferenciada de leite, com o uso de metodologias de extensão rural, promovendo a organização das famílias e o emprego de tecnologias sustentáveis, econômicas e adaptadas às condições edafoclimáticas da região.

\section{Sistema de Produção e Público}

Produção com base em pastagens perenes de verão e sobre semeadura de espécies de inverno, nas de pastagens comuns, área de lavoras anuais e áreas de caívas.

Público a ser buscado:

a) Famílias já na atividade;

b) Famílias com interesse;

c) Famílias a serem motivadas.

\section{Ações Diferenciadas a serem desenvolvidas}

-Organização das Famílias produtoras de leite;

-Implantação da Central de Inseminação;

-Programa de Irrigação de Pastagens;

-Certificação Sanitária das Propriedades (Brucelose e Tuberculose);

-Projeto da melhor Qualidade do Leite, a cargo do IFSC;

-Uso de alternativas de para diminuir a demanda por energia elétrica;

-Captação e uso de água da chuva. 


\section{Organização e Planejamento}

Ações e atividades para buscar uma organização coletiva, identificando os pontos com maior dificuldade e as soluções coletivas através de um planejamento participativo;

Organização grupal das famílias conforme a situação de cada Município;Construção de um planejamento participativo com cada grupo, definindo:

a) Os assuntos técnicos, gerenciais e outros;

b) Número de encontros para o ano organizado num calendário;

c) Locais para os encontros (Roteiro de propriedades);

d) Experimentadores e Unidades de Referência Técnica(URTs).

Logística

\section{Justificativa}

O Planalto Norte Catarinense tem potencial para se transformar em um polo de Lácteos com qualidade diferenciada, levando-se em consideração fatores humanos, geográficos, clima e solo favoráveis.

\section{Objetivo Geral}

Aumentar a capacidade produtiva da bacia leiteira do Planalto Norte, de forma integrada com as diversas entidades, instituições e produtores propiciando renda e fortalecendo a economia regional.

\section{Plano de Ação}

-Divulgação do Programa e marketing, junto às regiões de alto poder aquisitivo dentro do Estado outros grandes centros consumidores;

- Trabalho junto às redes de supermercados locais para que o produto Planorte Leite tenha lugar de destaque nas gôndolas;

-Preços Competitivos: alguns fatores como localização geográfica são altamente favoráveis impactando positivamente no custo do transporte que poderão ser beneficiados com incentivos de âmbito estadual, principalmente ICMS;

- Tributos Estaduais: constituir Grupo de Trabalho em parceria com as Agências de Desenvolvimento Regional, no sentido de construir pacote de incentivos que atinjam iniciativas que venham ao encontro ao projeto; 
-Inclusão da produção dos derivados do leite na merenda escolar de todos os municípios abrangidos pelo programa;

-Participação efetiva dos municípios através das Secretarias Municipais de Obras/Agricultura, no que se refere às vias vicinais propiciando condições mínimas de trafego observando que a coleta de leite é diária;

-Infra Estrutura Interna das Propriedades: intensificação dos programas já existentes em algumas prefeituras, do tipo "Porteira Adentra";

-Constituição de Fundo Municipal específico para apoiar o programa Planorte Leite, por todas as Prefeituras Municipais participantes;

-Estrutura mínima das Secretarias Municipais de Agricultura: equipe técnica e infraestrutura física para atendimento das demandas municipais do programa;

-Inclusão na programação dos eventos municipais/regionais existentes e criação de eventos específicos com vistas ao fortalecimento do Planorte Leite; ex. feiras, seminários, concursos, torneios etc.;

-Contratação de uma consultoria para estudo de uma proposta diferenciada para a industrialização do leite na região;

-Patrulha Mecanizada: constituir através de Consórcio Público, patrulha mecanizada para dar suporte à cadeia produtiva do leite;

-Uso obrigatório da logomarca "Planorte Leite" e do baner por todas as Entidades signatárias nos eventos relacionados à cadeia do leite como forma de valorizar e solidificar o Programa;

-Viabilizar uma logística única para aquisição e transporte dos insumos alternativos existentes na região (adubos orgânicos, resíduos das indústrias de papel, pó de rocha, etc).

Ações Diferenciadas e Metas Propostas para o Programa

-Estruturação do trabalho com espírito associativo entre as Instituições e os produtores;

-Criação do consorcio "CODEPLAN" para gerenciamento administrativo e financeiro de ações do Programa;

-Estruturação da patrulha mecanizada para auxiliar as Prefeituras em estradas com linha de coleta de leite;

-Certificação das propriedades como livres de brucelose e tuberculose;

-Busca da excelência na qualidade do leite produzido na região; 
-Uso de aquecedores de água com fontes alternativas de energia, (lenha, biogás e solar), para higienização dos equipamentos de ordenha (equipamento este, uma criação com ideia e informações geradas regionalmente);

-Estruturação da assistência clínica veterinária por intermédio do Consorcio;

-Dinamização ou criação dos Fundos Municipais de Desenvolvimento Agropecuário para gerenciar recursos financeiros e ações do Planorte Leite;

-Dinamização e reestruturação das Secretarias Municipais de Agricultura para serem as gestoras das principais ações do programa;

-Criação da Unidade de Treinamento de Inseminadores do Planalto Norte (Central de Inseminação) para que em $50 \%$ das famílias tenha um membro capacitado a fim de realizar a inseminação

-Estímulo para as propriedades especializadas que farão a criação de terneiras e novilhas;

-Compra de sêmen feito de forma integrada pelas Secretarias Municipais de Agricultura;

-Ações integradas entre as Secretarias Municipais de Agricultura;

-Ações junto às famílias de produtores que propiciem saúde e bem estar;

-Ingresso de 300 famílias por ano na atividade leiteira, objetivando o alcance de 5.000 famílias;

-Implantação e manejo de 1.300 hectares de pastagens perenes de verão com sobre semeadura de inverno por ano;

-Alcançar na região uma produção diária de 500.000 litros;

-Logística para promover maior utilização de insumos alternativos existentes na região na formação e produção das pastagens;

-Criação do projeto "Irrigar Pastagens";

-Organizar o trabalho de inspeção animal nos municípios através do CODEPLAN;

-Promover trabalho pedagógico junto aos alunos e professores das escolas estaduais e municipais através de visitação as propriedades leiteiras, para valorizar a atividade e despertar o conhecimento da importância do leite como alimento e meio de vida. 


\section{UMA CONTEXTUALIZAÇÃO E EXPLICITAÇÃO DOS FATORES FAVORÁVEIS AO PROGRAMA PLANORTE LEITE}

A conjuntura econômica do Brasil neste início de século XXI tem sido favorável ao desenvolvimento regional, já que houve melhoria significativa na renda da população brasileira no período de 2000 a 2012, conforme se visualiza na Figura 1.

Desta forma, o Brasil deste milênio tem um potencial de consumo muito maior do que tinha no século XX, o que se traduz no aumento da demanda por produtos lácteos.

Aliado a esses fatores conjunturais, a pecuária de leite tem recebido estímulos e incentivos por parte dos governos federal, estaduais e municipais, o que aumenta a possibilidade de obter êxito no programa PLANORTE LEITE. Além disso, existem outros fatores que favorecem o crescimento da produção leiteira no Planalto Norte, como adiante salientamos.

Figura 1 - Constituição das classes sociais no Brasil - 2002 e 2010

Aumento da renda e melhores oportunidades de trabalho levaram 32 milhōes de brasileiros para a classe média

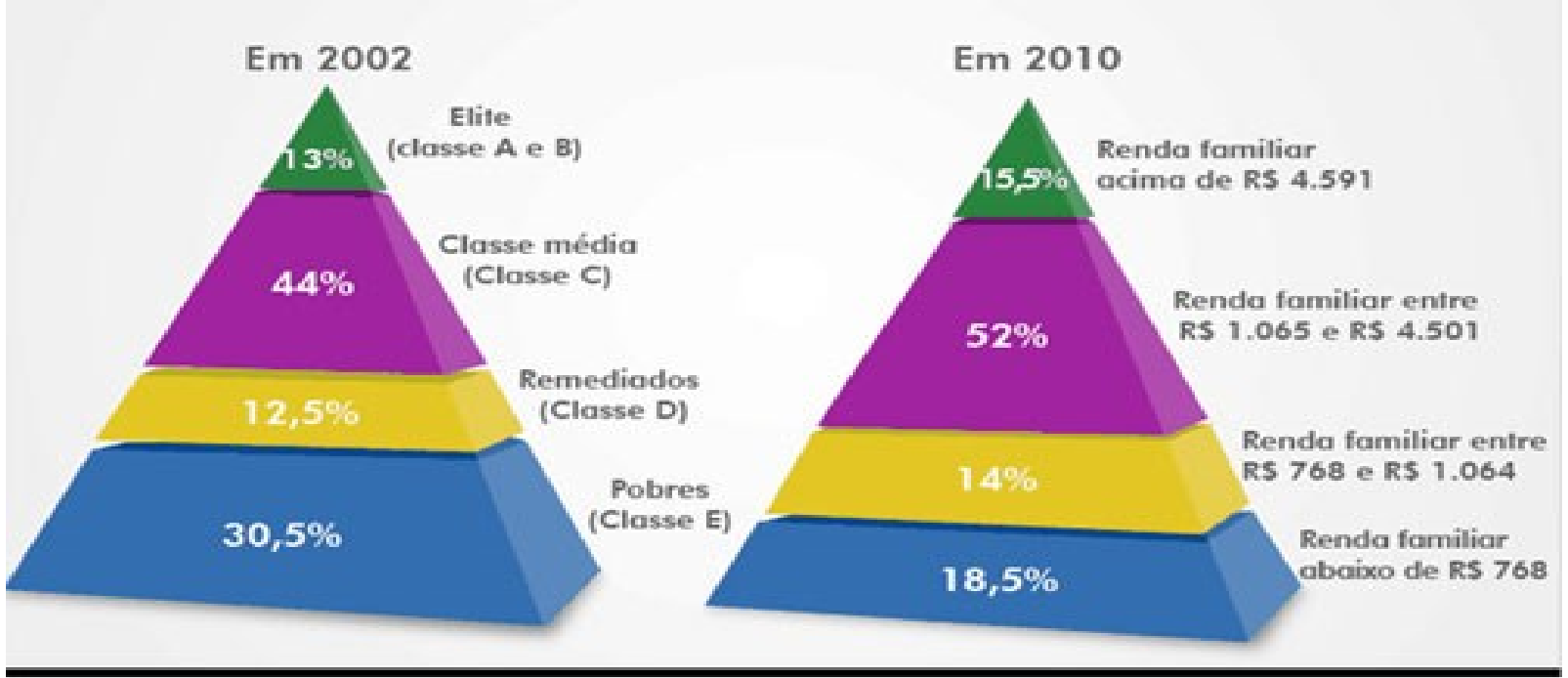

Fonte: Coelho (2012)

\section{a) Aumento da produção e do consumo mundial de leite}

Relatório da Organização das Nações Unidas para Alimentação e Agricultura (FAO) afirma que entre 2010 e 2020 a demanda mundial por produtos lácteos irá crescer $30 \%$.

\section{b) Potencial Produtivo da Região}

Nas Figuras 2 e 3 são apresentados dados sobre o potencial produtivo da região em referência. 
Figura 2 - Diagnóstico da atividade leiteira no Planalto Norte

\section{JIAGNÓSTICO DA ATIVIDADE LEITEIRA NO PLANALTO NORTE ESTIMATIVA PRELIMINAR - ANO 2012}

ÁREA TOTAL DA REGIÃO: 10.007.230 KM2 - (1.000.723 HÂ)

POPULAÇÃO TOTAL: HABITANTES: 345.200 - URBANA: 271.138 - POPULAÇÃO RURAL: 83.062

\begin{tabular}{|c|c|c|c|c|c|c|c|c|c|c|c|}
\hline $\begin{array}{c}\text { NÚMERO } \\
\text { DE } \\
\text { ESTABELIC. } \\
\text { AGROP. }\end{array}$ & \begin{tabular}{|c} 
NÚMERO \\
DE \\
FAMILIA \\
S \\
NO \\
MEO \\
RURAL
\end{tabular} & $\begin{array}{c}\text { NÚMERO } \\
\text { DE } \\
\text { ESTABELIC } \\
\text {. COM } \\
\text { LAVOURA } \\
\text { S TEMP. }\end{array}$ & \begin{tabular}{|c|} 
ÁREA \\
DE \\
LAVOURA \\
S TEMP. \\
(HÁ)
\end{tabular} & $\begin{array}{c}\text { ÁREA } \\
\text { DE } \\
\text { PASTAGEN } \\
\text { S } \\
\text { NATURAIS } \\
\text { (HÁ) }\end{array}$ & $\begin{array}{c}\text { ÁREA } \\
\text { DE } \\
\text { PASTAGENS } \\
\text { PLANTADAS } \\
\text { (HÁ) }\end{array}$ & $\begin{array}{c}\text { ÁREA } \\
\text { DE } \\
\text { PASTAGENS } \\
\text { EM } \\
\text { SISTEMAS } \\
\text { AGROFLOR. } \\
\text { (HÁ) }\end{array}$ & \begin{tabular}{|c|} 
NÚMERO \\
DE \\
ESTABELIC \\
$\cdot$ \\
AGROP. \\
COM \\
BOVINO
\end{tabular} & \begin{tabular}{|c|} 
NÚMERO \\
DE \\
VACAS \\
ORDENHADAS \\
NO \\
ANO
\end{tabular} & $\begin{array}{c}\text { TOTAL } \\
\text { DE } \\
\text { LETE } \\
\text { PRODUZID } \\
\text { O NO } \\
\text { ANO } \\
(1.000 \text { L) }\end{array}$ & $\begin{array}{c}\text { TOTAL } \\
\text { DE } \\
\text { LETE } \\
\text { VENDIDO } \\
\text { NO } \\
\text { ANO } \\
(1.000 L)\end{array}$ & $\begin{array}{l}\text { MÉDIA } \\
\text { DE } \\
\text { LITRO } \\
\text { S } \\
\text { POR } \\
\text { VACA } \\
\text { (DIA) }\end{array}$ \\
\hline 14.245 & 30.162 & 12.530 & 210.385 & 46.450 & 14.085 & 20.130 & 8.604 & 21.690 & 49.631 & 34.339 & 6.09 \\
\hline
\end{tabular}

Fonte: Epagri/CEPA - IBGE/Canoinhas

Elaboração: Epagri/CEPA - Canoinhas

Fonte: Epagri/CEPA (2016)

Figura 3 - Participação por região na produção de leite em SC (2012)

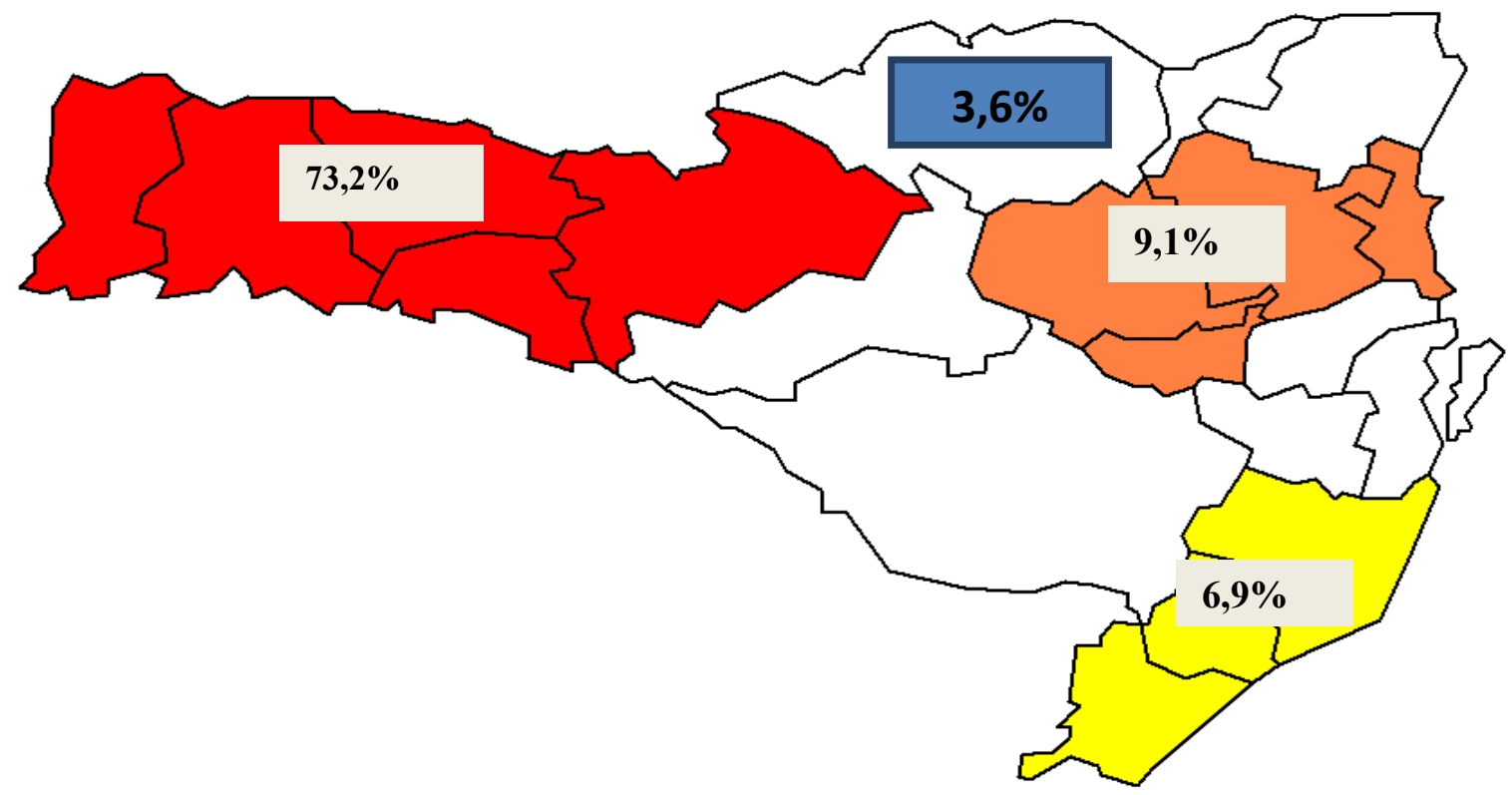

Fonte: IBGE (2010)

A Figura 2 apresenta a situação atual da produção e a participação da região na produção total de Santa Catarina, revelando a pouca expressão no contexto. Mas, a Figura 1 revela o grande potencial para a produção leiteira que a região apresenta, tanto com aumento da produtividade, como através da expansão das áreas de pasto e do número de propriedades. $\mathrm{O}$ grande potencial que se apresenta de forma diferenciada, constituem áreas de pastagens naturais e de sistemas agroflerstais, que somam mais de sessenta e cinco mil hectares, que,

DRd - Desenvolvimento Regional em debate (ISSNe 2237-9029) 
segundo pesquisas realizadas pela Epagri, revelam o grande potencial produtivo de pastagens, desde que adotadas as técnologias apropriadas para estas áreas e já disponíveis.

\section{c) Aumento da captação de leite pelas indústrias de SC}

Verifica-se na Figura 4 que há um crescimento sólido ao longo do tempo da captação de leite pelas indústrias de $\mathrm{SC}$, o que demonstra a viabilidade no aumento da produção. Como o Planalto Norte detém uma das melhores áreas para a produção de forragens, favorecendo em muito o aumento da produção leiteira.

Figura 4 - Captação de leite pelas indústrias de Santa Catarina

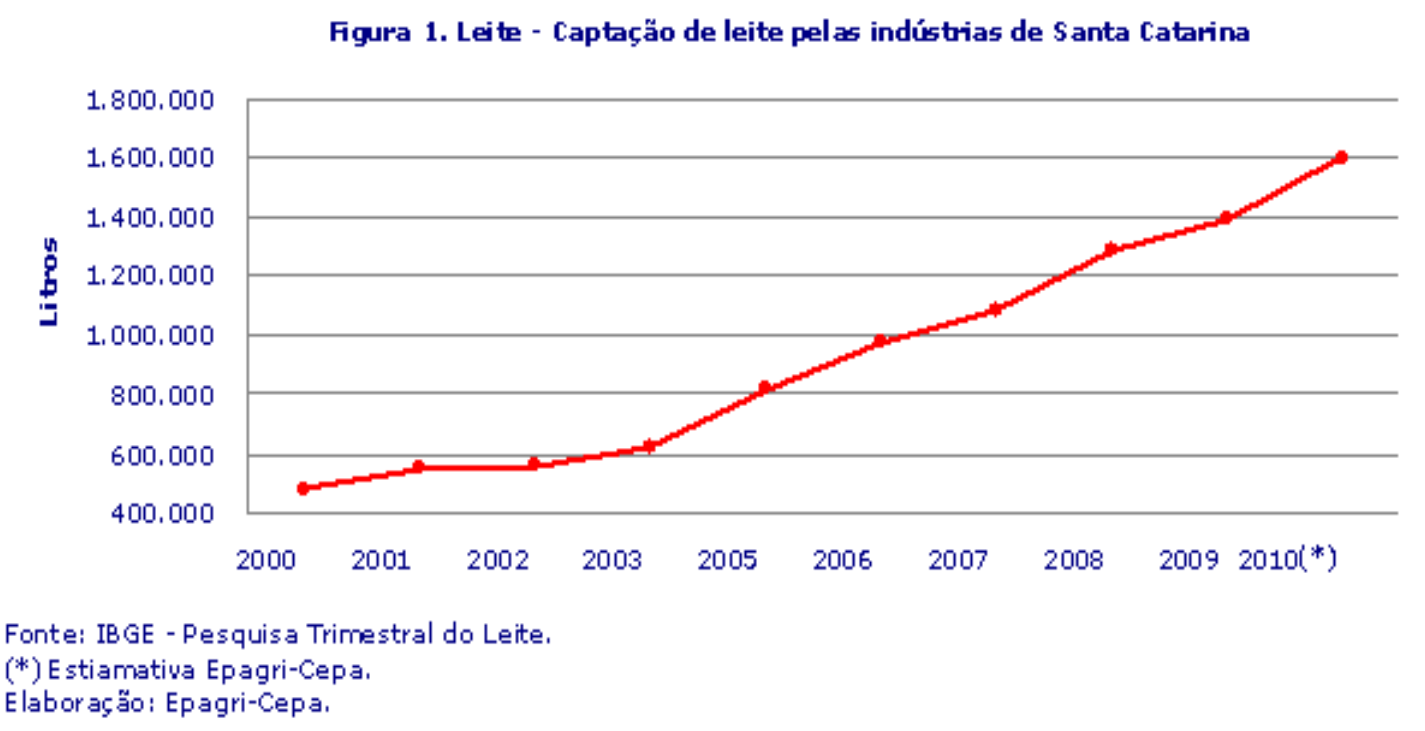

\section{d) A litoralização da população catarinense}

Este é um dos fatores que mais contribui para a viabilização do aumento da produção leiteira no Planalto Norte de SC. Está havendo um processo de migração dos municípios do interior do estado para as regiões litorâneas gerando importantes centros consumidores de alimentos.

Dessa forma, constata-se que o Planalto Norte Catarinense é uma das primeiras regiões agrícolas situadas acima da Serra do Mar, representando uma oportunidade impar de suprir esses municípios da região litorânea com produtos lácteos diferenciados.

\section{e) Crescimento do PIB per capita catarinense}

Este também é um fator que contribui positivamente para fortalecer o Planorte Leite. $\mathrm{O}$ aumento da renda per capita catarinense apresentou um aumento de $34,7 \%$ no período de 2002 a 2010, segundo dados do Departamento de Pesquisas e Estudos Econômicos-DEPEC. 
Estes dados indicam que houve um aumento no poder aquisitivo da população catarinense, que se reflete no consumo e nas vendas.

\section{f) Estrutura fundiária do Planalto Norte de SC}

A estrutura fundiária dos municípios do Planalto Norte Catarinense, mostra que 92,5\% das propriedades possuem área menor que 100 há e exploradas em regime familiar. É nesta estratificação e regime que se realiza a atividade leiteira atualmente e será o foco do Planorte Leite.

\section{g) Aumento da produtividade}

Pode ser estimulada com a adoção de práticas de manejo nas propriedades, sem aumentar os custos de produção. Segundo dados do IBGE/Epagri, a média de litros de leite produzidos por vaca dia na região é de 6,09 litros, o que é considerado baixo se comparado a outras regiões. Com a adoção de novas práticas na atividade, propostas no Planorte Leite, esta média poderá ser aumentada para 9,13 litros por vaca ao dia, o que já aumentaria em $50 \%$ a atual produção regional.

\section{h) Possibilidade de inserir novas áreas de pastos perenes}

O programa Planorte Leite propõe que 5\% das áreas hoje ocupadas com culturas anuais possam ser transformadas em pastagens perenes de verão. Outra proposição é melhorar as áreas de caivas e de pastagens comuns com a introdução de espécies forrageiras de verão e inverno adaptadas à região, como mostra a foto abaixo. Com isso haveria um incremento na produção leiteira da região em mais de 420 mil litros ao dia.

\section{i) Aumento da produção leiteira no Planalto Norte de SC}

No Planalto Norte Catarinense a produção leiteira apresentou um sensível aumento no ano de 2011, em relação a 2010, de acordo com dados do IBGE Cidades. Observa-se que houve um aumento de 4\% na produção de leite neste período. Em 2012, levantamento efetuado pela Epagri, Regional de Canoinhas, constatou que houve um aumento de 7,79\% em relação ao ano de 2011. Isso ocorreu sem que houvesse grande estímulo, o que indica que, tendo o programa Planorte Leite implantado e pactuado entre os signatários, poderá haver um crescimento significativo destes percentuais nos próximos anos.

\section{f) Condições muito favoráveis de topografia, clima e solo para a produção leiteira}

Resultados de pesquisas realizadas pela Estação Experimental da Epagri de Canoinhas demonstram o grande potencial de produção de pastagens com alta qualidade.

\section{g. Espírito associativo}

É presente nas famílias de produtores de leite razoável espirito associativo, como demonstrado pela existência das quatro cooperativas de produtores de leite (Major Vieira, Monte Castelo, Papanduva e Porto União). 


\section{h. Mercado} região.

Existem mais de uma dezena de empresas e cooperativas coletoras de leite atuando na

\section{RESULTADOS ALCANÇADOS ATÉ O MOMENTO: PROTOCOLO DE COMPROMETIMENTO DAS ENTIDADES PARCEIRAS}

Apresentamos na sequência, protocolo firmado entre as instituições articuladoras e apoiadoras do Programa Planorte Leite, conforme descrito na sequência.

A entidades signatárias, abaixo denominadas, firmam o presente protocolo de comprometimento, visando o desenvolvimento sustentável do Planalto Norte de Santa Catarina, através da implementação do Programa Planorte Leite, mediante as cláusulas e condições mencionadas a seguir.

\section{Cláusula Primeira - OBJETIVO}

O presente Protocolo tem o objetivo precípuo de promover a cooperação técnica, científica, financeira e educacional entre as instituições signatárias, visando desenvolver atividades voltadas para o fortalecimento da cadeia produtiva do leite no Planalto Norte de $\mathrm{SC}$.

\section{Cláusula Segunda - DA EXECUÇÃO E DOS COMPROMISSOS}

Para alcançar os objetivos definidos na cláusula anterior, as instituições signatárias se comprometem a executar as ações e atividades constantes no bojo do programa Planorte Leite.

Sub-cláusula Única: Toda e qualquer nova iniciativa tanto na área produtiva ou de industrialização que vier a ser proposta pelos signatários deverá ser apresentada e aprovada pela coordenação do programa - Ampla Norte.

\section{Cláusula Terceira - DA COORDENAÇÃO}

As Instituições signatárias concordam que a coordenação do Programa Planorte Leite seja exercida pela Associação de Municípios do Planalto Norte de SC-AMPLA NORTE.

Sub-cláusula Única: Para cada ação a ser desenvolvida poderá também ser criada uma Coordenação específica com representantes das Instituições executoras.

\section{Cláusula Quarta - DAS MODIFICAÇÕES}

Os signatários, de comum acordo e tendo em vista a conveniência e interesse pertinentes, poderão modificar os termos do presente Protocolo, desde que mantido o seu objeto e respeitada à legislação em vigor. 


\section{Cláusula Quinta - DA DENÚNCIA}

O presente Protocolo poderá ser denunciado a qualquer momento, desde que a parte interessada, justificadamente, notifique a outra, por escrito, com antecedência mínima de 90 (noventa) dias.

Sub-Clausula Única: No caso de denúncia, havendo pendências ou trabalhos em execução, os signatários definirão, através de um Termo de Encerramento do Protocolo, as responsabilidades relativas á conclusão ou extinção de cada um dos trabalhos e todas as demais pendências, inclusive as referentes ao destino de bens, os direitos autorais e de propriedade dos trabalhos em andamento, bem como ás restrições ao uso e divulgação de bens e informações colocadas á disposição dos signatários.

\section{Cláusula Sexta - DA VIGÊNCIA}

O presente protocolo entrará em vigor a partir da data de sua assinatura e terá vigência de 5 (cinco) anos, contados da sua publicação em instrumento oficial.

Sub-Cláusula Única: Havendo interesse das Instituições Signatárias, poderá o presente Protocolo ser prorrogado por igual período, devendo constar em termo próprio.

\section{Cláusula Sétima - DOS CASOS OMISSOS}

Os casos omissos e as dúvidas que se originarem em virtude do presente Protocolo, serão dirimidos pelos signatários mediante termo específico, se necessário, ou conforme disposto na legislação aplicável.

\section{Cláusula Oitava - OUTROS PARTÍCIPES}

Mediante concordância expressa das Instituições executoras de atividade específica, outros órgãos ou instituições poderão participar das ações específicas a serem desenvolvidos no âmbito deste protocolo.

E por estarem de pleno acordo com as cláusulas e condições acima estabelecidas, firma o presente Protocolo de Intenções em 3 (três) vias de igual teor e forma, perante as testemunhas abaixo subscritas. $\mathrm{O}$ documento foi elaborado e assinado pelas entidades parceiras em Canoinhas-SC, 23 de maio de 2014.

\section{CONSIDERAÇÕES FINAIS}

O crescimento e a consolidação da produção leiteira no Planalto Norte Catarinense passa pela organização e a consciencia associativa dos produtores, além do enganjamento das organizações na busca de uma produção diferenciada, para mercados diferenciados. As boas condições de clima e solo para a produção de pastagens, tanto de inverno como de verão e a localização geográfica favoravel a uma logística de mercado, são as condicionantes favoráveis da região para a aposta na produção diferenciada.

O desenvolvimento de produtos, máquinas e equipamentos tambem está sendo pensado, como plantadeiras para mudas de pastagem, enfardadeiras, sistemas de aquecimento de água com fontes alternativas de energía, como a solar, lenha e biogás. 
A organização das famílias em grupos formais e informais continuará sendo a tônica do trabalho da extensão rural e assistência técnica, tendo em vista os resultados já alcançados, como o exemplo das quatro cooperativas de produtores de leite da agricultura familiar, uma associação de produtores e mais de trinta grupos informais de famílias que estão sendo estruturados. Destes grupos, dez deles foram apoiados com recursos do programa estadual SC Rural, em mais de dois milhões e trezentos mil reais em recursos não reembolsáveis e que foram aplicados no sistema produtivo das propriedades, para melhorar a eficiência e a qualidade da produção.

Ações para a valorização da produção local e das pessoas envolvidas buscando a saúde e bem estar também estão sendo pensados, assim como, um trabalho com alunos da redes municipais e estaduais em parceriais com as famílias de produtores, para promover visitas nas propriedades, afim de que as crianças e jovens possam conhecer a rotina de uma propriedade e assim valorizar o produto leite e a produção local. Este trabalho tem previsão para iniciar em 2017.

Por fim, destaca-se que o programa Planorte Leite é a primeira iniciativa de organização de uma atividade agrícola no Planalto Norte Catarinense, envolvendo as famílias de produtores, técnicos, representantes das organizações dos produtores, lideranças, instituições públicas, privadas e de ensino, na busca de uma produção diferenciada e sustentável, com rentabilidade. Espera-se que dessa iniciativa resultem novas oportunidades de trabalho e renda para produtores rurais, com isso, contribuindo para o desenvolvimento regional.

\section{REFERÊNCIAS MENCIONADAS E SUGERIDAS PARA A APROFUNDAMENTO DO TEMA PRODUÇÃO LEITEIRA}

BOVINOCULTURA DE LEITE. Disponível em: <www.veterinariandocs.com. br $>$. Acesso em: 21 jun. 2016.

COELHO, L. C.; COELHO, L. R. As classes sociais e a desigualdade no Brasil. Disponível em $<$ http://www.logisticadescomplicada.com/as-classes-sociais-e-a-desigualdade-no-brasil/> Acesso em: 17 nov. 2012.

FACTORI, M. A. et. al. Módulos mínimos de produção: custos da produção de leite em pasto. Disponível em: $<$ http://www.milkpoint.com.br/radar-tecnico/pastagens/modulosminimos-de-producao-custos-da-producao-de-leite-em-pasto-68833n.aspx $>$. Acesso em: 21 jun. 2016.

FERRARI, L. F. et. al. Agricultores Familiares, Exclusão e Desafios para Inserção Econômica na Produção de Leite em Santa Catarina. Informações Econômicas, SP, v. 35, n.1, jan. 2005.

INSTITUTO BRASILEIRO DE GEOGRAFIA E ESTATÍSTICA-IBGE CIDADES.

Disponível em: <www.ibgecidades.org.br>. Acesso em: 21 jun. 2016. 
INSTITUTO BRASILEIRO DE GEOGRAFIA E ESTATÍSTICA-IBGE. Disponível em: $<$ www.ibge.org.br>. Acesso em: 21 jun. 2016.

MARCONDES, T. Considerações sobre a produção leiteira de Santa Catarina. EPAGRI/CEPA. I Seminário Territorial da Cadeia Leite no PNC. Canoinhas, Epagri, 2007.

MELLO, M. A. A trajetória da produção e transformação do leite no oeste catarinense e busca de vias alternativas. Florianópolis, UFSC, 1998. Dissertação (Mestrado em Agroecossistemas) - Centro de Ciências Agrárias, Universidade Federal de Santa Catarina, 1998.

MILKPOINT. Análise da elasticidade da renda e de consumo de leite no Brasil. Disponível em: $<$ http://www.milkpoint.com.br/cadeia-do-leite/espaco-aberto/analise-daselasticidades-renda-e-de-consumo-de-leite-no-brasil-73134n.aspx. Acesso em: 02 nov. 2012.

NOTÍCIAS AGRÍCOLAS. Leite: preço ao produtor é o maior em cinco anos, aponta Cepea, 29 maio 2013. Disponível em: <http://www.noticiasagricolas.com.br/analises/leitecepea/123067-leite-preco-ao-produtor-e-o-maior-em-cinco-anos--aponta-cepea.html $>$. Acesso em: 15 set.. 2015.

ORGANIZAÇÃO DAS NAÇÕES UNIDAS. Relatório da Organização das Nações Unidas para Alimentação e Agricultura (FAO), 2010.

SANTA CATARINA. Secretaria da Agricultura e Pesca do Estado. A escolha da trajetória da produção de leite como estratégia de desenvolvimento do oeste catarinense. Florianópolis: SAR, 2003.

SANTOS, O. V. et. al. Estudo da cadeia do leite em Santa Catarina: prospecção e demandas. Florianópolis: Epagri, 2006.

STULP, V.M. et. al. Caracterização da Cadeia Produtiva do Leite do Oeste de Santa Catarina. Congresso Internacional de Administração. Chapecó-SC, 2012. 